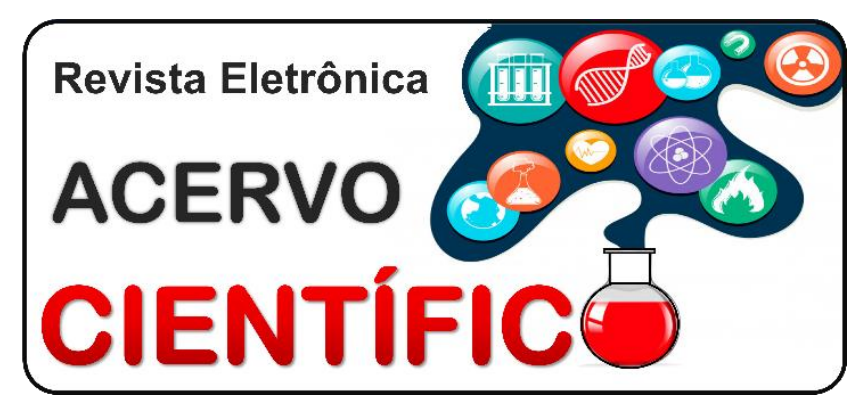

ESTUDO DE CASO

Recebido em: 3/2020

Aceito em: 4/2020

Publicado em: $7 / 2020$

\title{
Relato de caso: mieloma múltiplo diagnosticado em paciente jovem e com eletroforese de proteínas normal
}

\author{
Case report: multiple myeloma diagnosed in young patient and with normal protein \\ electrophoresis
}

Caso clínico: myeloma multiple diagnosticado en un paciente joven con electrophoresis
proteica normal

Caio Santiago Ferreira Coelho ${ }^{1 *}$, João Aprigio da Silva Neto ${ }^{1,2}$, Paulo de Tarso Talarico Zeme ${ }^{1,2}$, Patrícia Marques Mendes ${ }^{1,2}$, Wilson Cunha Junior ${ }^{1,2}$, Rodrigo Tavares Silva ${ }^{1,2}$.

\begin{abstract}
Resumo: O mieloma múltiplo (MM) é uma neoplasia maligna, progressiva e incurável. Acomete células do tipo $\mathrm{B}$, tendo como característica a proliferação descontrolada de plasmócitos. A prevalência é maior a partir da quinta década de vida, em homens e negros com história. É uma doença que apesar do tratamento, afeta qualidade de vida e não tem bom prognóstico. A maioria dos pacientes é sintomática e a dor óssea é o sintoma mais frequente. $O$ tratamento é feito com quimioterapia a depender do estadiamento. $O$ paciente estudado era do sexo masculino, 32 anos, pardo com queixa de 15 dias de dores intensas em região lombar, sem alívio com medicação, associado a vômitos e perda de peso. As tomografias de crânio e lombar demonstraram lesões líticas. A eletroforese de proteínas mostrou-se normal e o mielograma evidenciou $42 \%$ de plasmócitos, confirmando o diagnóstico com lesão renal aguda tratada na internação e foi encaminhado para tratamento. O diagnóstico de mieloma múltiplo pode ser feito nesse paciente pela apresentação de plasmocitose, hipercalcemia, lesão renal aguda. Evoluiu com anemia, além de dores como manifestação inicial. Divergiu da literatura, a idade do paciente, porém, etnia e sexo concordam com a literatura.
\end{abstract}

Palavras-chave: Adulto jovem, Diagnóstico precoce, Mieloma Múltiplo.

\begin{abstract}
Multiple myeloma (MM) is a malignant, progressive and incurable neoplasm. Affects type B cells, with uncontrolled proliferation of plasmocytes as a characteristic. Prevalence is higher from the fifth decade of life in men and blacks with family history. It is a disease that despite treatment, affects quality of life and does not have a good prognosis. Most patients are symptomatic and bone pain is the most frequent symptom. Treatment is done with cranial and lumbar tomography showed lytic lesions. Protein electrophoresis was normal and myelogram showed $42 \%$ of plasmocytes, confirming the diagnosis of. Progressed with acute kidney injury treated at the hospital and was referred for treatment. chemotherapy depending on the staging. The patient studied was male, 32-year-old male patient, paired with 15 days of severe pain in the lumbar region, without relief with medication, associated with vomiting and weight loss. The diagnosis of multiple myeloma can be made in this patient by presenting plasmocytosis, hypercalcemia, acute kidney injury and
\end{abstract}

1Universidade de Franca. Franca - SP. *E-mail: caiocoelho504@gmail.com

${ }^{2}$ Santa Casa de Misericórdia de Franca. Franca - SP. 
anemia, as well as pains such as initial manifestation. Diverged from the literature, the patient's age, however, ethnicity and sex agree with the literature.

Keywords: Young adult, Early diagnosis, Multiple myeloma.

Resumen: El mieloma múltiple (MM) es una neoplasia maligna, progresiva e incurable. Afecta a las células tipo B, con la característica de proliferación incontrolada de células plasmáticas. La prevalencia es mayor después de la quinta década de la vida, en hombres y negros con antecedentes. Es una enfermedad que, a pesar del tratamiento, afecta la calidad de vida y no tiene un buen pronóstico. La mayoría de los pacientes son sintomáticos y el dolor óseo es el síntoma más frecuente. El tratamiento se realiza con quimioterapia según la etapa. El paciente estudiado era hombre, de 32 años, marrón con 15 días de dolor intenso en la parte baja de la espalda, sin alivio con medicamentos, asociado con vómitos y pérdida de peso. Las tomografías computarizadas de cráneo y lumbares mostraron lesiones líticas. La electroforesis de proteínas fue normal y el mielograma mostró el $42 \%$ de las células plasmáticas, lo que confirma el diagnóstico. con lesión renal aguda tratada al ingreso y fue derivada para tratamiento. El diagnóstico de mieloma múltiple se puede hacer en este paciente al presentar plasmacitosis, hipercalcemia, daño renal agudo. Difería de la literatura, la edad del paciente, sin embargo, el origen étnico y el sexo están de acuerdo con la literatura.

Palabras clave: Adulto joven, Diagnóstico precoz, Mieloma múltiple.

\section{INTRODUÇÃO}

O Mieloma Múltiplo (MM), também conhecido como Doença de Kahler é um tipo de neoplasia maligna, progressiva e incurável. Representa 1\% das neoplasias malignas e é a segunda causa de neoplasia oncohematológica (10\%), ficando atrás somente do linfoma. Acomete células do tipo $\mathrm{B}$, tendo como característica a proliferação descontrolada de plasmócitos na medula óssea e com produção de imunoglobulinas anômalas monoclonais (proteína M), interferindo na produção das demais células sanguíneas (DIAS AG, et al., 2015) (FURINI AAC, et al., 2018).

O pico de prevalência é a partir da quinta década de vida, com incidência maior em homens e pacientes negros (DIAS AG, et al, 2015) (FURINI AAC, et al, 2018). Segundo Salema CLZ (2017), no Brasil, os diagnósticos são tardios e a média de idade é de 60,5 anos, na maioria com estágio avançado da doença. Atualmente, tem-se observado um aumento da prevalência mundial, o que pode ser explicado pela melhor condução dos casos e conhecimento da história natural e patogênese, melhores recursos laboratoriais, aumento da expectativa de vida e exposição crônica a agentes poluentes, radiação ionizante e profissões de risco (trabalhador rural). Além desses fatores de risco já descritos, a história familiar de primeiro grau, aumenta cerca de duas vezes o risco de desenvolver a doença (MILANI LZ e FERNANDES MS, 2018) (SILVA ROP, et al., 2009).

A maioria dos pacientes são sintomáticos $(66 \%)$ e a dor em ossos longos é o sintoma mais frequente (58\%). Outros sintomas comuns são: fraturas patológicas que levam a compressão medular, hipercalcemia e déficits neurológicos com perda sensorial e motora. Além disso, os pacientes podem apresentar sintomas inespecíficos como: perda de peso, fadiga, anorexia, febre e sonolência que são decorrentes da anemia. $O$ MM envolve sítios de todo o esqueleto e acomete preferencialmente o crânio (causando lesões líticas que também são chamadas de "lesões em sal e pimenta" devido ao aspecto das mesmas), costelas, esterno e ossos longos (DIAS AG, et al, 2015; MILANI LZ E FERNANDES MS, 2018).

O diagnóstico geralmente é feito através de eletroforese de proteínas, que ajuda, também, a discernir o tipo de MM (FURINI AAC, et al, 2018). Este pode ser realizado por exames laboratoriais que identificam e quantificam proteínas monoclonais no soro ou urina. Além disso, pode ser feito mielograma, imunofixação de proteínas e dosagem de cadeias leves e livres no sangue e exames complementares como hemograma completo, função renal, cálcio, radiografias, tomografias e ressonância do esqueleto e biópsia de medula óssea. De acordo com Salema CLZ (2017) e Sucro LV, et al (2009), uma das formas de confirmação do 
diagnóstico é a presença de pelo menos 2 dos 3 critérios a seguir: 1. CRAB (hipercalcemia, insuficiência renal, anemia e bone lesions - lesões ósseas); 2. presença sérica ou urinária de imunoglobulina monoclonal (proteína M); 3. Excesso de plasmócitos na medula óssea (acima de 10\%).

A insuficiência renal aguda causada no paciente é classificada pela Sociedade Brasileira de Nefrologia a partir de estágios pela classificação (National Kidney Fundation (KDIGO), sendo o 1 caracterizado por elevação de $0,3 \mathrm{mg} / \mathrm{dL}$ da creatinina serica basal ou aumento em 2 vezes, o estágio 2 um aumento de até 3 vezes e o estágio 3 elevação de mais de 3 vezes ou creatinina acima de $4 \mathrm{mg} / \mathrm{dL}$. Ela tem a função de uniformizar conceitos e facilitar o diagnóstico da síndrome com posterior redução de morbimortalidade. (YU L, et al, 2007).

O principal objetivo do tratamento é alterar a sobrevida e a qualidade de vida dos pacientes. Primeiramente eles são classificados em assintomáticos e sintomáticos. Os assintomáticos geralmente evoluem com sintomatologia em dois ou três anos, por isso deve-se permanecer uma vigilância clínica para acompanhamento e o tratamento será iniciado de acordo com as manifestações clínicas. Os pacientes sintomáticos são tratados com quimioterapia a depender do estadiamento. Quando apresentam complicações graves de anemia, função renal, lesões líticas, hipercalcemia, aumento do componente $\mathrm{M}$ no soro ou urina, eles se tornam candidatos a altas doses de quimioterapia e transplante autólogo de células troncohematopoiéticas. (SALEMA CLZ, 2017). Os pacientes têm a qualidade de vida bastante afetada, principalmente devido à anemia e à doença óssea. Apesar dos avanços das terapias na melhora da qualidade de vida, os efeitos adversos ainda são frequentes, causando complicações aos pacientes (MILANI LZ E FERNANDES MS, 2018).

O diagnóstico de MM em paciente jovem é bastante raro e, por este motivo, este relato tem o objetivo de dar importância para o diagnóstico precoce, o que pode resultar em melhora da qualidade de vida e do prognóstico dos pacientes com MM.

\section{RELATO DE CASO}

REFL, masculino, 32 anos, pardo, foi admitido em hospital terciário em abril de 2019, com queixa de 15 dias de dores intensas do tipo cólica (intensidade 10), em região lombar, sem alívio com medicação analgésica, piora ao caminhar e melhora com posição supina. Irradiou para abdome inferior, região torácica e precordial. Associado a isso, apresentava vômitos de coloração esverdeada e odor fétido e perda de $7 \mathrm{~kg}$. Ao exame físico, apresentava-se hipocorado, acantose nigricans em região cervical, abdome levemente doloroso à palpação profunda de hipocôndrio esquerdo, sem descompressão brusca e dor a punhopercussão em região lombar direita, sem outras alterações. Foi internado para a clínica médica devido a exames demonstrando hipercalcemia, além de hemograma e função renal alterados e tomografia computadorizada de crânio e coluna lombar com lesões líticas. Foi, então, elaborada a hipótese de mieloma múltiplo. Na internação, mantinha dores lombares apesar do uso de analgésicos, vômitos e hiporexia.

Durante a internação, o paciente foi acompanhado e avaliado em conjunto pela clínica médica e nefrologia devido ao diagnóstico de injúria renal aguda classificada pelo KDIGO, como já descrito e evoluiu com estágio 3 (elevação em 3 vezes da creatinina da linha de base ou creatinina acima de 4).

O tratamento durante toda a internação foi feito com analgésicos de média e alta potência, bicarbonato de sódio, dieta hipossódica e hemodiálise para tratamento renal.

$\mathrm{Na}$ alta, foi encaminhado para hospital especializado para tratamento e seguimento da neoplasia e para ambulatório de nefrologia para acompanhamento de lesão renal.

Nos exames de imagem realizados anexados abaixo (radiografia e tomografia computadorizada (TC) de crânio) pode-se notar as lesões osteolíticas, características do MM indicadas pelas setas. (Figuras 1 a 4). 
Tabela 1 - Exames laboratoriais realizados em dois dias diferentes e os respectivos valores de referência do laboratório que fez a análise.

\begin{tabular}{|c|c|c|c|}
\hline Tipo de exame & Primeira amostra & Segunda amostra & $\begin{array}{c}\text { Valores de referência } \\
\text { (VR) }\end{array}$ \\
\hline Hemoglobina & $9,5 \mathrm{~g} / \mathrm{dL}$ & $10 \mathrm{~g} / \mathrm{dL}$ & $13,0-17,5 \mathrm{~g} / \mathrm{dL}$ \\
\hline Plaqueta & $100.000 / \mu \mathrm{L}$ & $103.000 / \mu \mathrm{L}$ & $125.000-425.000 / \mu \mathrm{L}$ \\
\hline Urina 1 & $\begin{array}{l}\text { Proteínas presentes } \\
\text { Sangue oculto positivo } \\
\text { Leucocitúria } \\
\text { Hematúria } \\
\text { Cristais oxalato cálcio } \\
\text { Bacteriúria aumentada }\end{array}$ & Não realizado & $\begin{array}{l}\text { Proteínas ausentes } \\
\text { Sangue oculto negativo } \\
\text { Leucócitos: } 0-5 \text { por campo } \\
\text { Hemácias: menos que } 3 \\
\text { por campo } \\
\text { Cristais: ausentes } \\
\text { Bacteriúria: raras ou } \\
\text { ausentes }\end{array}$ \\
\hline Urocultura & Negativa & Não realizado & Negativo \\
\hline Creatinina & $3,6 \mathrm{~g} / \mathrm{dL}$ & $5,4 \mathrm{~g} / \mathrm{dL}$ & $0,4-1,3 \mathrm{mg} / \mathrm{dL}$ \\
\hline Cálcio & $14,2 \mathrm{mg} / \mathrm{dL}$ & $17,8 \mathrm{mg} / \mathrm{dL}$ & $8,5-10,5 \mathrm{mg} / \mathrm{dL}$ \\
\hline Cálcio iônico & $1,97 \mathrm{mmol} / \mathrm{L}$ & $2,05 \mathrm{mmol} / \mathrm{L}$ & $1-1,3 \mathrm{mmol} / \mathrm{L}$ \\
\hline Eletroforese de proteínas & $\begin{array}{l}\text { Pico monoclonal: ausente } \\
\text { Proteínas totais: } 5,1 \mathrm{~g} / \mathrm{dL} \\
\text { Albumina: } 3 \mathrm{~g} / \mathrm{dl} \\
\text { Beta-2-globulina: } 0,31 \\
\text { g/dL } \\
\text { Gama globulina: } 0,39 \mathrm{~g} / \mathrm{dL} \\
\text { Relação } \\
\text { albumina/globulina: } 1,47\end{array}$ & $\begin{array}{l}\text { Proteínas totais: } 5,1 \\
\text { g/dL } \\
\text { Albumina: } 3,23 \mathrm{~g} / \mathrm{dl} \\
\text { Beta-2-globulina: } \\
0,22 \text { g/dL } \\
\text { Gama globulina: } 0,24 \\
\text { g/dL } \\
\text { Relação } \\
\text { albumina/globulina: } \\
1,72\end{array}$ & $\begin{array}{l}\text { Pico monoclonal ausente } \\
\text { Proteínas totais: } 6,6-8,3 \\
\text { g/dL } \\
\text { Albumina: } 3,68-5,48 \mathrm{~g} / \mathrm{dl} \\
\text { Beta-2-globulina: } 0,21-0,54 \\
\text { g/dL } \\
\text { Gama globulina:0,73-1,56 } \\
\text { g/dL } \\
\text { Relação } \\
\text { albumina/globulina: } 0,8-2,2\end{array}$ \\
\hline Mielograma & $\begin{array}{l}\text { Hipercelularidade: } \\
42 \% \text { plasmócitos }\end{array}$ & Não realizado & 0-3,5\% de plasmócitos \\
\hline
\end{tabular}

Fonte: Coelho CSF, et al., 2019.

Figura 1 - RAIO - X com alteração textural óssea difusa da craniana determinada pela presença de múltiplas pequenas de aspecto lítico.

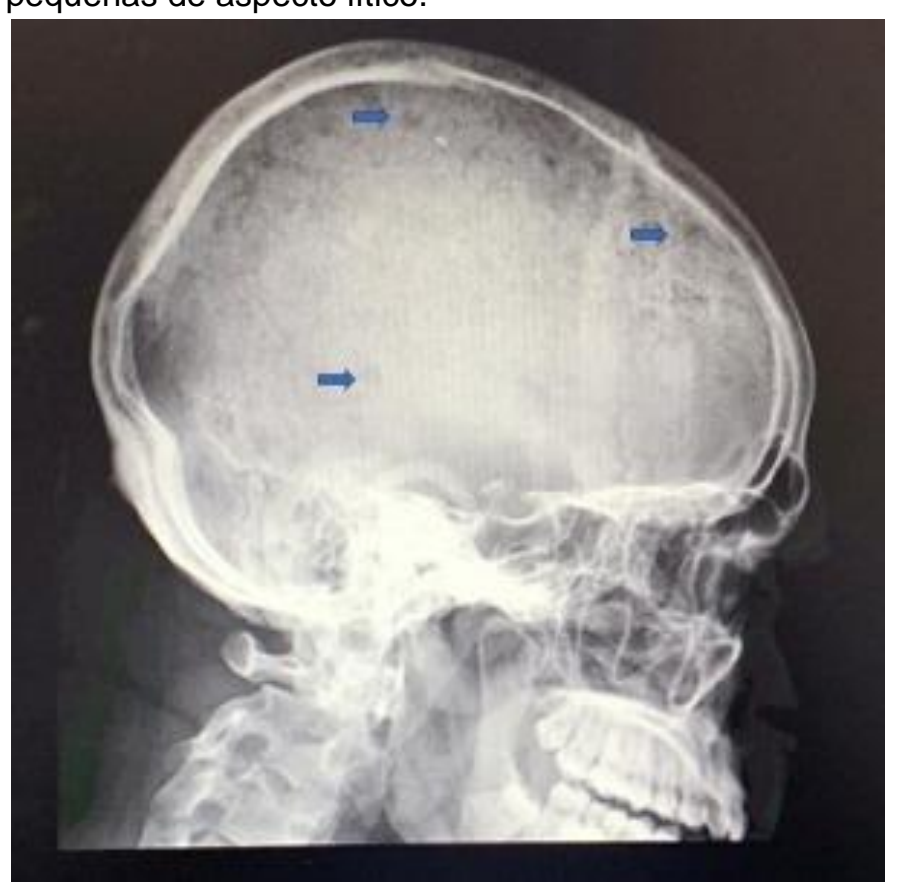

Fonte: Coelho CSF, et al, 2019. 
Figura 2 - RAIO - X com alteração textural óssea difusa da calota craniana determinada pela presença de múltiplas lesões pequenas lesões de aspecto lítico.

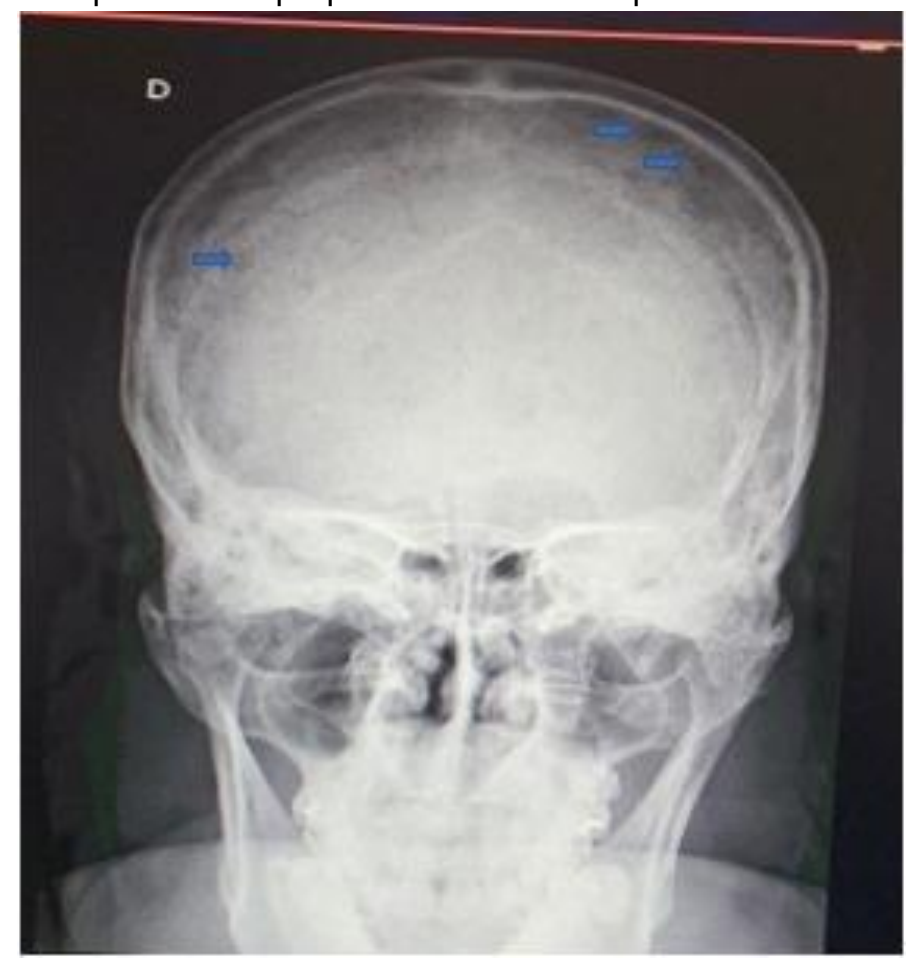

Fonte: Coelho CSF, et al, 2019.

Figura 3 - TC de crânio com lesões osteoíticas perfurantes (em sal e pimenta).

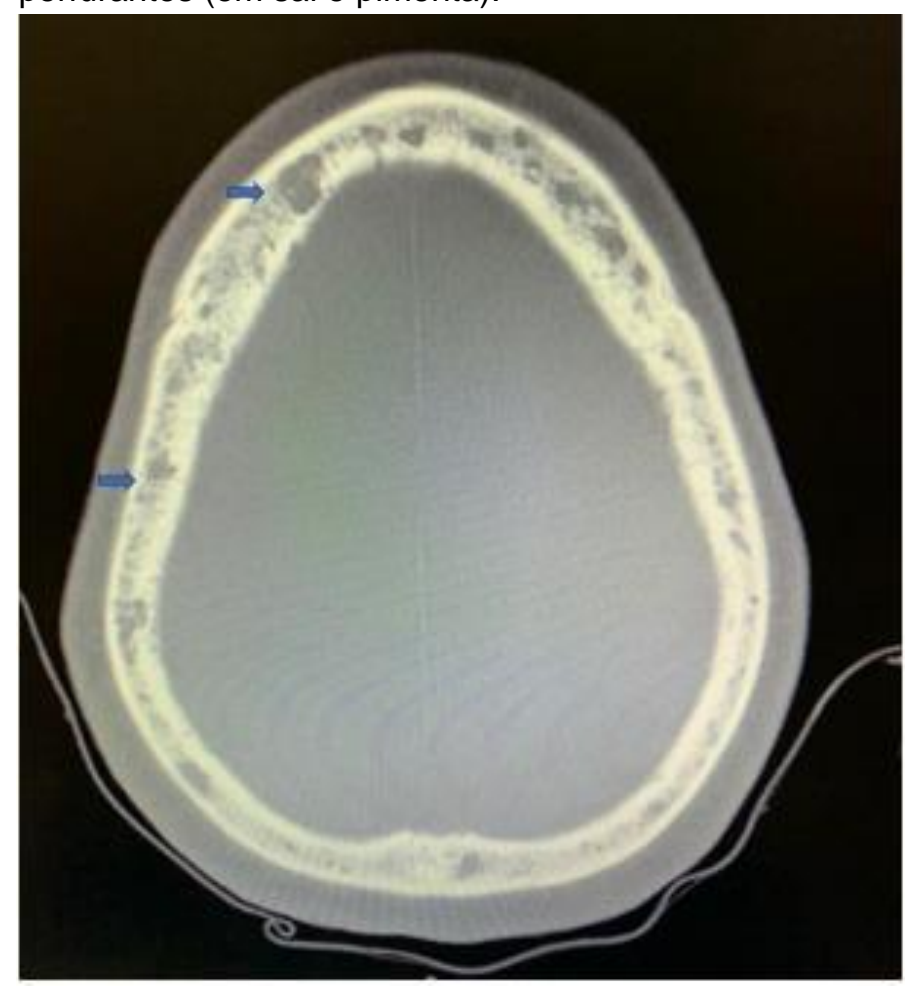

Fonte: Coelho CSF, et al, 2019. 
Figura 4 - TC de crânio com lesões osteoíticas perfurantes (em sal e pimenta).

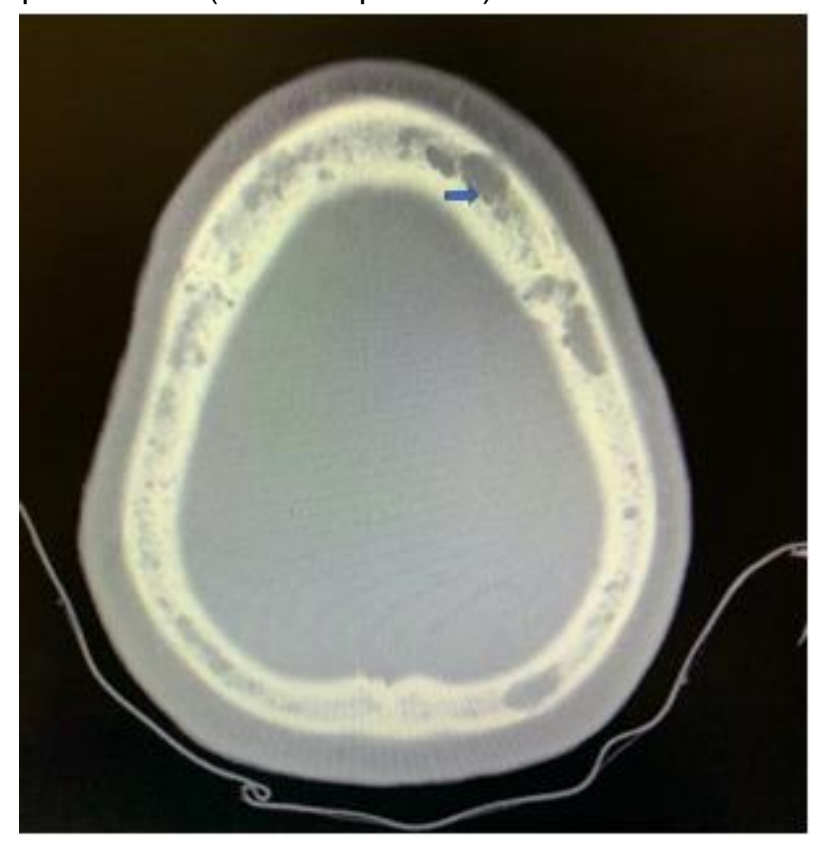

Fonte: Coelho CSF, et al, 2019

\section{DISCUSSÃO}

O primeiro passo na avaliação de um novo paciente com MM é diferenciar os estágios pré-malignos (gamopatia monoclonal de significância indeterminada (MGUS)) e a latência mieloma múltiplo (SMM) do MM propriamente dito. Deve-se determinar se a insuficiência renal, hipercalcemia, anemia e/ou lesões ósseas são devidas ao MM ou outro processo pois, para caracterizar MM o "dano ao órgão final" deve ser atribuído à discrasia das células plasmáticas (KLAUS DG, et al, 2009) (RAJKUMAR SV, et al, 2019). Devido ao estágio pré-maligno (MGUS) que pode se apresentar, o diagnóstico nos pacientes se dá a partir da quinta década de vida, antes disso, cerca de $3 \%$ da população se mantém no estágio assintomático e, destes, $1 \%$ ao ano, evoluiu para MM (RAJKUMAR SV, et al, 2018). Neste presente estudo, o paciente apresentou hipercalcemia, lesão renal, anemia, e lesões ósseas líticas que não eram explicadas por outras patologias, levantando a suspeita de MM, além de plasmocitose no mielograma. Além disso, houve a presença de $42 \%$ de plasmáticos nos exames realizados posteriormente.

De acordo com a literatura, o MM é mais comum nos afro-descendentes, em homens (3:2) e o risco aumenta com a idade. É uma doença incurável e a sobrevida é em média de 3 anos (SAKAE TM, et al, 2010). No caso em questão, o paciente era pardo e homem, mas o que discordou da literatura foi o diagnóstico do MM ser dado na terceira década de vida, idade em que os pacientes, geralmente, ainda estão no estágio prémaligno MGUS.

O sintoma principal encontrado nos pacientes ao início dos sintomas é a dor óssea, relacionada à destruição óssea que é causada pela multiplicação das células na medula óssea devido a ativação dos osteoclastos e diminuição dos osteoblastos. Muitas vezes este sintoma representa atividade neoplásica em estágio avançado. O diagnóstico, geralmente tardio, prejudica a qualidade de vida do paciente, pois o acometimento na maioria das vezes é vertebral com prejuízo da função mecânica (SALEMA CLZ e CARVALHO C, 2019). Neste estudo de caso, o paciente teve como manifestação inicial a dor lombar e torácica, mas, por ter tido diagnóstico precoce, espera-se melhores resultados da terapêutica.

A evolução para insuficiência renal com decréscimo na depuração da creatinina ocorre em $20 \%$ dos pacientes com MM evoluem para e $9 \%$ necessitam de terapia de substituição renal, principalmente hemodiálise (SAKAE TM, et al, 2010). Neste estudo, o paciente fez lesão renal aguda com creatinina que variou de 3,6 a 5,4 na internação, sendo necessária a realização de hemodiálise, o que condiz com os dados da literatura, e, na alta, foi encaminhado para o serviço de nefrologia. 
A anemia abrange cerca de $70 \%$ dos casos de pacientes com MM e é a complicação hematológica mais frequente. Dentro das principais causas estão sangramento gastrointestinal, nefrotoxicidade induzida por antiinflamatórios não esteroidais e efeito mielossupressão do tratamento anti neoplásico (SALEMA CLZ e CARVALHO C, 2019). Pode-se avaliar na tabela 1 a presença de anemia moderada ( $\mathrm{Hb}$ de 9,5 e 10 nos dois exames realizados) e uma das explicações para tal pode ter sido o uso de analgésicos para dor.

A contribuição das imagens na patologia em questão se dá de modo pouco sensível pela radiografia, que possui sensibilidade a depender de haver destruição óssea local de 30 a 50\%, e deve ser utilizada apenas na ausência de demais exames mais sensíveis, como a tomografia computadorizada e a ressonância magnetica. (RAJKUMAR SV, et al, 2014) Houve compatibilidade com o caso estudado, visto que ambos exames de imagem já apresentavam as alterações osteolíticas no momento do diagnóstico.

A eletroforese ou imunofixação de proteínas séricas/urinárias deve ser sempre solicitada em pacientes com suspeita de MM para realização de diagnóstico, estadiamento e seguimento. Ela apresenta alteração sérica em $80 \%$ dos casos e $75 \%$ das vezes na urina. O principal objetivo deste exame é definir o tipo de proteínas anormais de cadeias leves e pesadas envolvidas na doença (DIAS AG, et al, 2015). A eletroforese de proteínas deste paciente teve resultado normal, fazendo parte este, da minoria dos casos já estudados. Apesar disso, o diagnóstico não é afastado, já que esta não é a única forma de diagnóstico e o paciente apresentou outros dados passíveis de confirmação diagnóstica. A situação pode ser observada em estudos que revelam que até $18,8 \%$ dos pacientes diagnosticados com mieloma múltiplo não apresentavam pico monoclonal sérico, não se enquadrando na maioria dos casos onde geralmente há alteração de cadeias de imunoglobulinas. (SILVA ROP, et al, 2009).

Além disso, a eletroforese de proteínas negativa do caso em questão pode ter se encontrado na pequena porcentagem de falso-negativos do teste, uma vez que o mesmo possui a sensibilidade de $80,4 \%$ e especificidade de $77,9 \%$ como mostra a Diretriz de Mieloma Multiplo da Associação Médica Brasileira. (HUNGRIA VTM, et al, 2013).

Antes do tratamento, o paciente deve ser avaliado globalmente quanto a extensão da doença, comorbidades prévias e estratificação de risco para, só assim, ser iniciado o tratamento específico (RAJKUMAR SV, et al, 2018).

Devido aos sintomas inespecíficos e proximidade deles com outras patologias, muitas vezes os profissionais da saúde não conseguem fazer diagnóstico precoce da doença. Isso pode resultar em pior prognóstico e evolução. (DIAS AG, et al, 2015). Por isso, é importante que os profissionais da saúde saibam reconhecer ou ao menos suspeitar desta patologia para que as complicações consigam ser melhor prevenidas e exista alguma possibilidade de terapêutica ao diagnóstico.

\section{CONSIDERAÇÕES FINAIS}

O Mieloma Múltiplo se caracteriza como uma neoplasia prevalente, porém com dificuldades no diagnóstico precoce. Sendo assim, os sistemas de educação continuada para os profissionais de saúde, principalmente da Atenção Primária, são relevantes para a melhoria do padrão diagnóstico desta doença no Brasil. Para isso, deve-se ter frequentemente, campanhas educacionais para a população, disponibilização da solicitação de exames complementares com facilidade e protocolos de investigação mesmo nos níveis básicos de atenção. Dessa forma, as complicações serão mais bem prevenidas, influenciando positivamente na sobrevida e qualidade de vida devido ao acesso à terapêutica e encaminhamentos às especialidades apropriadas a cada caso.

\section{AGRADECIMENTOS}

Nossos votos à Universidade de Franca por permitir aos alunos buscarem uma formação médica integral, voltada a todas as possibilidades de medicina e sendo a pesquisa uma porta de entrada para o futuro. Agradecemos também a Santa Casa de Misericórdia de Franca que estimula a produção de artigos e trabalhos contribuindo assim para a formação de acervos na área da saúde e permite fomentar a medicina baseada em evidências. 


\section{REFERÊNCIAS}

1. DIAS AG, et al. Caracterização dos sinais e sintomas clínicos do mieloma múltiplo e os atuais métodos de diagnóstico laboratorias. Uningá Review, 2015; 21 (1): 11-16.

2. FURINI AAC, et al. Perfil de pacientes com diagnóstico patológico de mieloma múltiplo em hospital de ensino. Arq. Ciênc. Saúde, 2018; 25(1): 61-64.

3. HUNGRIA VTM, et al. Mieloma Multiplo. Associação Brasileira de Hematologia e Hemoterapia e Terapia Celular, Oct 30, 2013.

4. KLAUS DG, et al. Caso clássico de mieloma múltiplo: uma revisão. Arquivos catarinenses de medicina, 2009; 38(4): 110-113.

5. MILANI LZ, FERNANDES MS. Abordagem inicial ao paciente com suspeita de mieloma múltiplo. Acta médica, 2018; 39 (2): 29-36.

6. RAJKUMAR SV, et al. International Myeloma Working Group Updated Criteria for the Diagnosis of Multiple Mieloma, Lancet Oncol. Nov, 2014.

7. RAJKUMAR SV, et al. Multiple myeloma: Overview of management. This topic last updated: Feb 27, 2019.

8. RAJKUMAR SV, et al. Multiple myeloma: Pathobiology. This topic last updated: Sep 10, 2018.

9. SAKAE TM, et al. Sobrevida de pacientes portadores de mieloma múltiplo atendidos em hospital de referências no sul de Santa Catarina. Rev. Bras Clin. Med, 2010; 8 (3): 216-221.

10. SALEMA CLZ, CARVALHO C. Diagnósticos, tratamentos e prognósticos do mieloma múltiplo. Rev. Cien. Saúde, 2019; 4 (1): 1-9.

11. SALEMA CLZ. A importância do diagnóstico precoce para o tratamento do mieloma múltiplo. [Monografia] Pindamonhangaba: Faculdade de Pindamonhangaba; 2017

12. SILVA ROP, et al. Mieloma múltiplo: característica clínica e laboratoriais ao diagnóstico e estudo prognóstico. Rev. Bras. de Hematol. Hemoter, 2009; 31 (2): 61-63.

13. SUCRO LV, et al. Mieloma múltiplo: diagnóstico e tratamento. Rev. Med. Minas Gerais, 2009; 19(1): 58-62.

14. YU L, et al. Insuficiência renal aguda. Diretrizes da AMB sociedade brasileira de nefrologia. 2007. 